\title{
ICONOGRAFÍA DE LOS TESTIGOS DE LOS PROCESOS TERESIANOS. A PROPÓSITO DE ADRIAN COLLAERT Y LA ESCENOGRAFÍA DE LA CAPILLA CORNARO
}

\author{
FERnANDo Moreno CUADRo \\ Universidad de Córdoba
}

\begin{abstract}
El trabajo se centra en los testigos de los procesos teresianos de beatificación y canonización que se recuerdan por los artistas con la intención de servir de referente al espectador para que se sitúe en el lugar de los atestiguantes "de visu", como nuevos refrendarios de las escenas que representan momentos singulares de la vida de la reformadora descalza y sucesos prodigiosos debidos a la intervención divina. No es un tipo de figuración frecuente y menos aún la de los "testigos de referencia" que confirman lo narrado de generación en generación, aunque éstos se destacan de manera especial en la capilla Cornaro de Santa Maria della Vittoria de Roma, vinculada a una estampa de Collaert, que sirvió a Bernini para plantear la ubicación de los miembros de la importante familia veneciana contemplando el Éxtasis de Santa Teresa.

Palabras clave: Contrarreforma; Estampa; Carmelitas; Procesos de beatificación y canonización; Capilla Cornaro.
\end{abstract}

\section{ICONOGRAPHY OF THE WITNESSES TO TERESIAN PROCESSES. CONCERNING ADRIAN COLLAERT AND THE SCENOGRAPHY OF THE CORNARO CHAPEL}

This study focuses on the witnesses of the Teresian beatification and canonization processes remembered by the artists with the intention of serving as a reference to the spectator in order to put themselves in the position of "de visu" witnesses, as new testifiers of the scenes depicting key moments in the life of the barefoot reformer and of prodigious events caused by divine intervention. It is not a common type of figuration, especially that of the "reference witnesses" who confirm what is narrated from generation to generation, although the latter are highlighted in a special way in the Cornaro Chapel in Santa Maria della Vittoria in Rome, linked to a print by Collaert, which Bernini used to fix the location of the members of this important Venetian family contemplating the Ecstasy of Saint Teresa.

Key words: Counter-Reformation; Print; Carmelites; Beatification and canonization process; Cornaro Chapel.

En la preparación de las "positiones" de los procesos de beatificación y canonización, con todos los datos que se envían a la Congregación para las Causas de los Santos para su examen, tienen un importante papel los testimonios de los testigos de la fase informativa que permiten 
establecer el grado heroico en que vivió las virtudes cristianas y la fama de santidad de quien se quiere presentar como modelo de vida a la Cristiandad, a la que se da a conocer por el actor que los promueve, su familia religiosa, editando textos biográficos y estampas ${ }^{1}$.

En la primera etapa de los procesos de la reformadora carmelita tuvo un papel fundamental Juan de Jesús María ${ }^{2}$-Prepósito General de los Descalzos- que dedicó tres libros a la santa abulense, en los que sintetizó la tradición doctrinal teresiana ${ }^{3}$, y redactó el Compendivm vitae B. V. Teresiae a Iesu (Roma, 1609) que presentó a Paulo V, a quien solicitó la beatificación de la reformadora descalza, proclamada el 24 de abril de 1614 por el Breve Regis aeternae, a la que precedieron varias publicaciones, entre las que destacan la del padre Jerónimo Gracián, Declaración en que se trata de la perfecta vida y virtudes heroicas de la B. Madre Teresa de Jesús y de las fundaciones de sus monasterios (Bruselas, 1611) y su primera vida ilustrada, la Vita B. Virginis Teresiae a Iesu, bajo la dirección de Adrian Collaert y Cornelio Galle, que tuvo una amplia repercusión artística en Europa ${ }^{4}$ y América ${ }^{5}$.

En la Vita de Amberes se figuran por primera vez los testigos que, con el paso del tiempo y terminados los procesos, se mantuvieron en determinadas obras con la finalidad de hacer partícipe al espectador de las mismas de la espiritualidad teresiana, continuando la motivación principal de la primera vida efigiada de santa Teresa, que se expone de forma inusual en la dedicatoria latina a su benefactor, don Rodrigo Lasso Niño -conde de Añover, Administrador y Camarero Mayor del Serenísimo Archiduque Alberto-, subrayando que fue creada con la intención de llegar "con esta ayuda para los ojos" a un mayor número de fieles, despertando su admiración y suscitando la imitación de la santa de Ávila, pues su vida "tantas veces escrita y leída, penetra poco en los espíritus", esperando un solo fruto, el de la piedad ${ }^{6}$, es decir, la acción de personas de vida religiosa sincera, tan afín con el espíritu de Trento, que en la sesión XXV recogió: "Enseñen con esmero los Obispos que por medio de las historias de nuestra redención, expresadas en pinturas y otras copias, se instruye y confirma al pueblo recordándole los artículos de la fe, y recapacitándole continuamente en ellos: además que se saca mucho fruto de todas las sagradas imágenes, no sólo porque recuerdan al pueblo los beneficios y dones que Cristo les ha concedido, sino también porque se exponen a los ojos de los fieles los saludables ejemplos de los santos, y los milagros que Dios ha obrado por ellos, con el fin de que den gracias a Dios por ellos, y arreglen su vida y costumbres a los ejemplos de los mismos santos; así como para que se exciten a adorar, y amar a Dios, y practicar la piedad".

En la serie de Collaert-Galle, que puede considerarse el germen de la iconografía teresiana, se recogen varias escenas con personajes que participan en las mismas y por tanto testigos implicados, cuyos testimonios son fundamentales en las primeras fases del proceso. Hay algunas

Procesos de beatificación y canonización de Santa Teresa de Jesús, 1934-1935.

2 Para su biografía, véanse Di Bernardino, 1994 y GIL DE Muro, 1996.

$3 \mathrm{Su}$ amplia producción literaria está recogida en Opera Omnia, publicada en Colonia en 1650. La edición más completa es la dirigida por Giovanni Strina, en 28 volúmenes. Edit. MTh Soumillion, Bruselas, 1993-1997.

4 Véanse, entre otros, Emond, 1961, Gutiérrez Rueda, 1964 y Calvo Castellón, 1975.

${ }_{5}^{5}$ Recordar las cinco series pintadas derivadas de ella en Hispanoamérica. Las de los Claustros del Carmen Alto de Quito del siglo XVIII (Ecuador) -la del claustro bajo, con pocos lienzos, y la del claustro alto en pinturas murales del XVIII (MeboldK, 1985: 54-107)- y las tres series del siglo XVII que presentan un mejor estado de conservación y mayor interés, la pintada por José Espinoza de los Monteros para el convento de Santa Teresa del Cuzco (Perú), en 1682, y las dos series de Santiago de Chile fechadas en torno a 1691, cuando ingresa en el convento Ana de Jesús, que las entrega como dote (MESA-GISBERT, 1962).

6 "Fructum vnvm speramus, Pietatis; vt si scripta toties lectaque minùs se in animos B. TERESIAE caelestis vita penetret, hoc adiumento oculis subiecta fidelibus, admirationem gignat, suscitet aemulationem" (Un solo fruto esperamos, el de la Piedad; pues si la celestial vida de la Beata Teresa, tantas veces escrita y leída, penetra poco en los espíritus, ojalá que ofrecida con esta ayuda a los ojos de los fieles haga nacer la admiración y suscite la imitación).

Arch. esp. arte, LXXXVII, 345, ENERO-MARZO 2014, 29-44 ISSN: 0004-0428, eISSN: 1988-8511, doi: 10.3989/aearte.2014.03 
que reflejan los hitos más importantes de su vida monástica, partiendo del Ingreso en el convento, como la Premonición de muchos sucesos durante una grave enfermedad ${ }^{7}$ o el Encuentro de santa Teresa con san Juan de la Cruz en Duruelo para exhortarlo a que adoptara la Regla primitiva del Carmelo. La Vita recoge el trascendental encuentro con el reformador descalzo ${ }^{8}$, utilizando la estampa flamenca de 1613 el recurso del observador asomándose tras la puerta, posiblemente la portera, que no participa pero testifica la llegada al monasterio de Duruelo de san Juan de la Cruz, en una solución poco habitual, pues presenta a las carmelitas saliendo de la clausura para recibir a los visitantes, figuración heterodoxa ${ }^{9}$ que no cambia hasta las estampas de Palomino (1752) que los sitúa en un interior ${ }^{10}$-no en el locutorio, como hubiera sido normal-, en el que santa Teresa instruye a san Juan ${ }^{11}$.

El papel del testigo comienza a adquirir cada vez mayor protagonismo en la iconografía teresiana y se introduce en temáticas que en principio no parecían necesitarlo, como la de escritora -no obstante ser uno de los elementos fundamentales en los procesos de beatificación, en los que una comisión de teólogos analiza con detalle la pureza doctrinaria en el juicio de ortodoxia-, porque la fama y rectitud de los escritos teresianos, que le valieron en 1970 el título de Doctora de la Iglesia Universal, reservado a quienes han tenido una trascendencia decisiva en el magisterio Universal de la fe, no ofrecían duda y así debió entenderse por los mentores de la Vita de Amberes, en la que se figura la santa en el momento en que recibe la inspiración divina con un versículo de la Vulgata, "Spiritu intelligentiae repleuit illam" (Eclo 39,8), referente al escriba que consagra su vida al estudio, "Publica las enseñanzas de su doctrina / y se gloriará en conocer la ley y la divina alianza. / De muchos será alabada su inteligencia, / y jamás será echado en olvido. / No se borrará su memoria, y su nombre vivirá de generación en generación" (Eclo, 39 11-13).

Es una representación que se matiza en la estampa grabada por Francisco Villamena con motivo de la beatificación de santa Teresa (1614), en la que se introducen otros aspectos fundamentales en la vida de la reformadora (Fig. 1). En ella se destaca asimismo la presencia del testigo que relata la influencia que recibió del Espíritu Santo, como sujeto paciente de una acción extraordinaria de la divinidad, mientras realiza su importante labor intelectual que la convierte en madre espiritual -de los fieles en general y de los descalzos en particular-, actividad que se completa con otras tareas de la vida activa que le permiten progresar en la contemplativa. Todo ello latente en la intimidad de su celda, en la que aparece la santa delante de un catre bajo una pintura del Ecce Homo, símbolos pasionistas y una pequeña alacena con libros, en el momento en que es observada por una descalza cuando recibe la inspiración divina para escribir, sentada en su pupitre, con libros y los símbolos de la efímera existencia -reloj de arena y calavera-, en torno al cual aparecen más libros -recalcando la tarea fundamental-, instrumentos de penitencia y de labor en un cesto de mimbre: huso de hilar, ovillo, paño de tela y tijeras, que complementaban la tarea intelectual/doctrinal con la labores de la vida cotidiana, símbolo de la fortaleza y la humildad que posibilitan progresar en la oración ${ }^{12}$.

\footnotetext{
7 "Graui infirmitate laborans, cum per quatriduum, omnium indicio mortua crederetur; plurima cum circa Ordinis sui reformationem olim euentura, tum circa sanctitatis suae praeconia, et parentum saluationem, in mentis exceso praecognoscit" (Padeciendo una grave enfermedad, se la dio por muerta durante cuatro días; durante su éxtasis tuvo premonición de muchos sucesos, tanto de la futura reforma de su Orden como del anuncio de su santidad y de la salvación de sus padres).

8 SANTA TERESA DE Jesús, Fundaciones: 3, 17

9 Excepcional fue la representación de Arnold van Westerhout que figura a san Juan recibiendo a la santa. Fue un tema tratado por Bouttats en la serie dedicada en 1675 al santo de Fontiveros, en la que recoge la vigilia del encuentro y la instrucción del mismo por santa Teresa.

10 Moreno Cuadro, 2010: 49-51.

11 Santa Teresa de Jesús, Fundaciones: 13, 5.

12 Santa Teresa de Jesús, Camino de Perfección: 17, 2-7.
}

Arch. esp. arte, LXXXVII, 345, ENERO-MARZO 2014, 29-44

ISSN: 0004-0428, eISSN: 1988-8511, doi: 10.3989/aearte.2014.03 


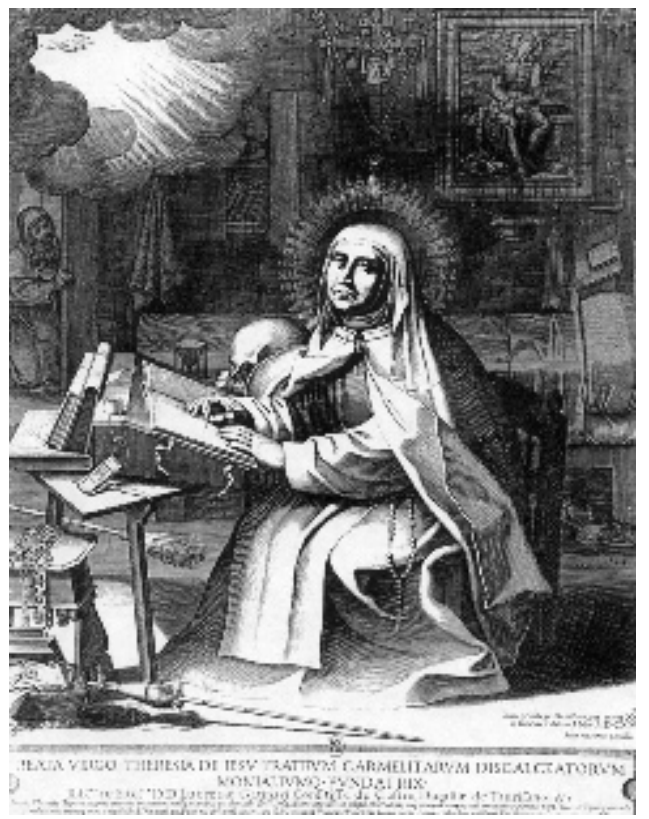

Fig. 1. Francisco Villamena, Santa Teresa escritora. Instituto Histórico. Teresianum de Roma.

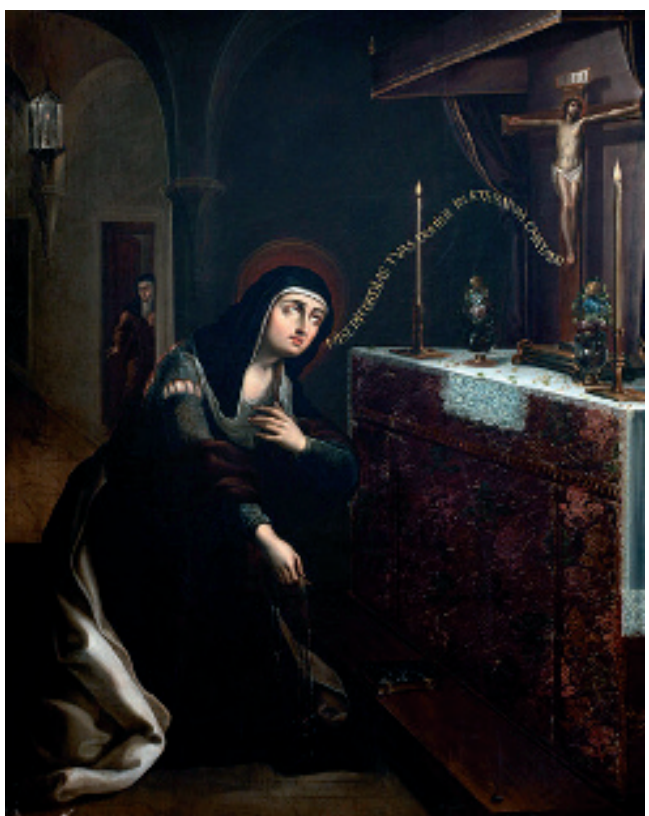

Fig. 2. Cristóbal de Villalpando, Santa Teresa mortificándose. Museo de El Carmen. México.

Se trata, en definitiva, de poner de manifiesto la singularidad del fiel que la Iglesia muestra como ejemplo a seguir, lo que se remarca en las series romanas de 1670 y 1715 con unas estampas tardías -que no están destinadas a apoyar las causas llevadas a Roma, sino que se realizan para difundir los distintivos de la reformadora descalza, completando las temáticas de la serie de Amberes del primer cuarto del siglo XVII-, en las que se figuran los testigos del éxtasis de santa Teresa tras escuchar un cántico sobre la hermosura divina. La Vita Effigiata ... ${ }^{13}$ la presenta de medio cuerpo, como en algunos arrobamientos ligados a la transverberación, mientras que en la serie setecentista aparece santa Teresa arrodillada ante un altar con un crucifijo ${ }^{14}$, observada por unas monjas -como en la estampa seiscentista- que Westerhout graba al fondo, bajo una arcada, formando una composición que podemos relacionar con el lienzo de Cristóbal de Villalpando del Museo de El Carmen de México que muestra a la santa mortificándose ${ }^{15}$ (Fig. 2), un tema que apareció en la Vita... de Amberes de 1613, cuyo planteamiento recuerda, incidiendo en el importante papel que la penitencia tuvo en la Idea Vitae Teresianae, en la que la alegoría se presenta al servicio de la mística y la espiritualidad teresiana con un claro sentido pedagógico que parte del conocimiento de sí mismo y persigue la unión con Dios, que se alcanza mediante la mortificación, la práctica de las virtudes y la oración mental que lleva a los desposorios espirituales, las cinco partes en que se divide la obra, publicada en Amberes por Jacques Mesens -sin fecha, c. $1686^{16}$ - y dedicada al Padre Huberto de S. Juan Bautista, Provincial de los carmelitas descalzos en Flandes-Bélgica, pues se entendía que la vida del cristiano debía ser una comunión de

13 Vita Effigiata et Essercizi Affettivi di s. Teresa di Giesv..., 1670: 32.

14 Vita Effigiata della Seráfica Vergine S. Teresa di Gesù..., 1715: lám. XLIX.

15 Gutiérrez Haces, 1997: 145.

16 Portman, 1974: 46. 


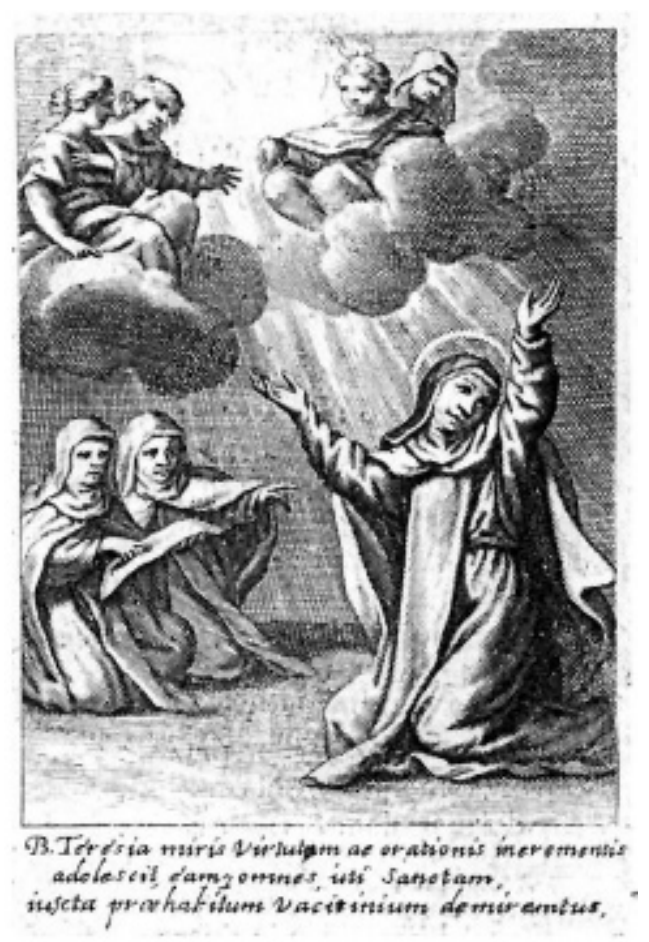

Fig. 3. Incremento de las virtudes de Santa Teresa, en Vita effigiata..., Roma, 1670. Teresianum de Roma.
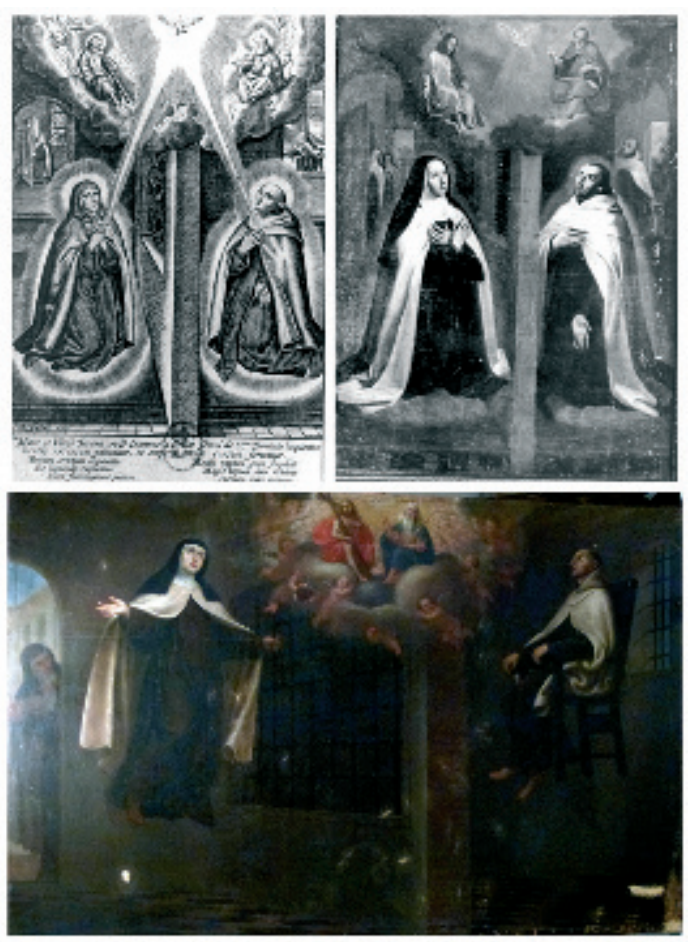

Fig. 4. J. Messager, Diálogo de Santa Teresa y San Juan de la Cruz sobre la Santísima Trinidad en el locutorio de la Encarnación de Ávila, Gabinete de Estampas de París, y versión pintada del Carmelo de Chalons (arriba). J. García Hidalgo, Santa Teresa y San Juan de la Cruz en el locutorio del monasterio de la Encarnación de Ávila dialogando sobre la Santísima Trinidad, Museo de Segovia (abajo).

muerte y de vida con Cristo crucificado y resucitado, que debía ser llevada al extremo por el religioso que al ingresar en la vida monástica se comprometía a la penitencia y mortificación referida por san Bernardo ${ }^{17}$.

No podían faltar los testigos que ratificaron el incremento de virtudes en santa Teresa, de la que admiraban su fama de santidad, especialmente sus hermanas de religión, representadas en las series de 1670 simbólicamente tras la protagonista y bajo la figuración de las virtudes ${ }^{18}$, sin atributos, excepto la que presenta en la cabeza una llama, que la identifica con la caridad, "sobre cuya cabeza - escribe Cesare Ripa- se verá una llama que representa su corazón ardiente"19 (Fig. 3).

17 Véase al respecto, LlOMPART, 1965: 159-172; 1973: 54-55.

18 Vita Effigiata et Essercizi..., 1970: 9; La Vie de la seraphiqve Mere Sainte Teresa de Iesvs, 1670: 39. Con el texto explicativo: "B. Teresia miris Virtutum ac orationis incrementis / adolescit eamquem omnes uti Sanctam / iusta proehabitum vaticinium demirantur" (La beata Teresa crece con admirable incremento de virtudes y oración, y todos la admiran como a santa, según un anterior vaticinio) que en la estampa de Lyon elimina el incremento de la oración y el vaticinio.

19 RIPA, 1987: t. I. p. 162.

Arch. esp. arte, LXXXVII, 345, ENERO-MARZO 2014, 29-44

ISSN: 0004-0428, eISSN: 1988-8511, doi: 10.3989/aearte.2014.03 
Los testimonios de su fama de santidad se simultanean con las representaciones de los testigos de su fervor e interés por las cosas sobrenaturales, destacando el diálogo sobre el Misterio de la Santísima Trinidad en el locutorio del convento de la Encarnación de Ávila que tuvo un amplio desarrollo en la iconografía teresiano-sanjuaniana, con diferentes variantes, entre las que nos interesa resaltar las que subrayan la temática de los testigos teresianos, con la representación de los dos santos en éxtasis, tal como los figura el lienzo del Carmelo de Chalons, de escuela francesa del siglo XVII ${ }^{20}$, el cual sigue de cerca la estampa de Jean Messager que, a su vez, se inspira en otra de Philippe y Carel de Mallery. La obra muestra a los dos protagonistas, observados por los atestiguantes -como en el ejemplar de la colección del marqués de Piedras Albas ${ }^{21}$ - bajo la Santísima Trinidad, a los lados de la reja del locutorio, de forma simétrica y en plano de igualdad, elevados sobre unas nubes. Ligeramente simplificada se reproduce la temática en un lienzo de colección particular de Madrid atribuido a Lucas Jordán ${ }^{22}$ y una singular variante es la que presenta José García Hidalgo en el cuadro del Museo de Segovia, donde aparecen los dos santos en el famoso diálogo del monasterio abulense en la víspera de la festividad de la Santísima Trinidad $^{23}$ (Fig. 4).

También hay escenas de hechos excepcionales que se comparten por los testigos, tal es el caso de la Curación de un pariente cuando quedó sepultado por una pared al construirse el primer convento descalzo y de Santa Teresa guiada por ángeles cuando se dirigía a fundar en Salamanca, con paralelismos iconográficos en las pinturas de san Francisco en las que aparece el santo guiado por ángeles con antorchas que le ayudan a cruzar los pantanos en la oscuridad. En la misma línea habría que incluir la Liberación del sacerdote sacrílego ${ }^{24} \mathrm{y}$, especialmente, la Muerte de santa Teresa asistida por Cristo en presencia de ángeles y tres santos, que en versiones posteriores se identifican con María y san José, al tiempo que se añaden miembros de la Orden ${ }^{25}$.

Todas poseen el denominador común de lo insólito, son sucesos prodigiosos que se producen por intervención divina, y tienen una gran repercusión para su familia religiosa, de ahí la presencia de testigos, especialmente en el momento de su muerte, en el que se asocia lo desacostumbrado con lo terrenal, subrayando como en los momentos previos a recibir el viático se dirigió a sus seguidoras para decirles "Hijas mías y señoras mías, pídoles por amor a Dios tengan gran cuenta con la guarda de sus reglas y constituciones" 26 , fundamentales para el Carmelo teresiano que promovió la causa de beatificación y quiere destacar la importancia de la descalcez promovida por la reformadora, quien se muestra como intercesora ante Dios en la curación milagrosa de su pariente ${ }^{27}$, que Adrian Collaert sitúa -recordando el accidente a través de una puerta abierta al exterior- en una capilla monacal con un altar presidido por un crucificado, ante el que se arrodilla santa Teresa con el pequeño en brazos, a diferencia de otras figuraciones que lo representan como un muchacho, suplicando a Dios por su vida (Fig. 5).

Escena que pone de manifiesto las señales divinas necesarias para la promulgación del auto apostólico en el que el papa declara a un siervo de Dios beato de la Iglesia y que aparece figu-

${ }^{20}$ L'Art du XVIIe siècle dans les Carmels de France, 1982: 73.

21 Gutiérrez RuedA, 1964: 34.

22 GutiérRez RuedA, 1964: 34.

23 URREA, 1975: 78 ss.

24 Santa Teresa de Jesús, Vida: 38.

25 Calvo Castellón, 1975: 266-272.

26 Biblioteca Mística Carmelitana: t. 18, 105.

27 "Dum Deo duce properat ad primi monasterij constructionem, consobrinum infantulum, parietis ruinâ suffocatum, fiducia exuberans Virgo, Deo suppliciter commendat: mox vitae reddit, et charo pignore moestam matrem solatur" (Cuando por inspiración divina se dispone a construir el primer convento, esta virgen, rebosante de fe, encomienda suplicante a Dios a un primo hermano suyo de corta edad, ahogado por el derrumbe de una pared: al punto vuelve a la vida, y consuela a la triste madre con esta adorable prenda).

Arch. esp. arte, LXXXVII, 345, ENERO-MARZO 2014, 29-44 ISSN: 0004-0428, eISSN: 1988-8511, doi: 10.3989/aearte.2014.03 

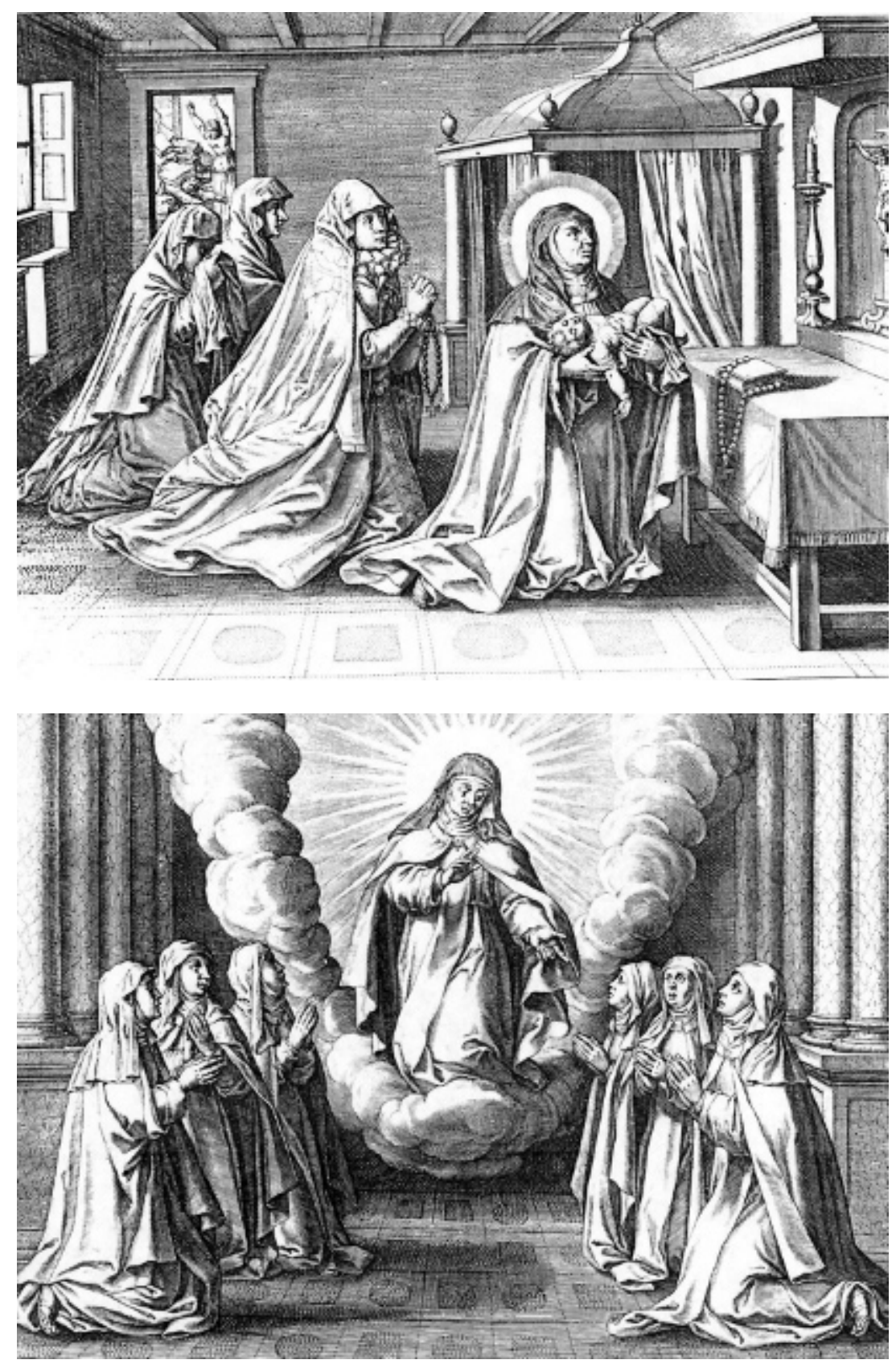

Fig. 5. Adrian Collaert, Curación de un pariente de Santa Teresa, en Vita B. Virginis Teresiae...., Amberes, 1613. Teresianum de Roma.

Fig. 6. Adrian Collaert, Aparición de santa Teresa tras su muerte a las carmelitas de Segovia, en Vita B. Virginis Teresiae...., Amberes, 1613.

Teresianum de Roma.

rada en varias series pintadas destinadas a decorar iglesias y monasterios carmelitas, después de ser admitida por la Iglesia, según promulgó el Concilio de Trento, que en su sesión XXV ordenó "a todos los Obispos, y demás personas que tienen el cargo y obligación de enseñar, que instruyan con exactitud a los fieles ante todas cosas, sobre la intercesión e invocación de los santos, honor de las reliquias, y uso legítimo de las imágenes, según la costumbre de la Iglesia Católica y Apostólica... (estableciendo) que a nadie sea lícito poner, ni procurar se ponga ninguna imagen

Arch. esp. arte, LXXXVII, 345, ENERO-MARZO 2014, 29-44

ISSN: 0004-0428, eISSN: 1988-8511, doi: 10.3989/aearte.2014.03 
desusada y nueva en lugar ninguno, ni iglesia, aunque sea de cualquier modo exenta, a no tener la aprobación del Obispo. Tampoco se han de admitir nuevos milagros, ni adoptar nuevas reliquias, a no reconocerlas y aprobarlas el mismo Obispo. Y este luego que se certifique en algún punto perteneciente a ellas, consulte algunos teólogos y otras personas piadosas, y haga lo que juzgare convenir a la verdad y piedad".

Los participantes no solo son testigos de hechos y virtudes, sino también de la experiencia teresiana de Dios, incidiendo en su magisterio, recordando especialmente sus apariciones y su oración. Entre las primeras, destaca la Aparición de santa Teresa tras su muerte a las carmelitas de Segovia, recogida en una estampa de Collaert que muestra a la reformadora entre nubes con forma de "V" cuando se dirige a seis de sus seguidoras de Castilla (Fig. 6). Es una de las pocas representaciones de apariciones, aunque en el pie de la estampa se recoge que lo hizo frecuentemente reluciendo en brillante gloria ${ }^{28}$, recordando la propia figuración lo que repetía a las descalzas con insistencia: "no nos cansemos de alabar a tan gran Rey y Señor, que nos tiene aparejado un reino que no tiene fin, por unos trabajillos en mil contentos, que se acabarán mañana. Sea por siempre bendito, amén, amén" ${ }^{29}$. Enseñanza que se evoca en el frontispicio de Les oevvres de la Sainte Mere..., publicadas en París en 1657, que muestra a santa Teresa como madre de los descalzos, a los que guía con sus escritos y conduce a la divinidad, idea que Juan Bernabé Palomino grabó para ilustrar el Camino de perfección en la edición de la Imprenta del Mercurio de Madrid en 1752 de las Cartas y Obras de santa Teresa de Jesús ${ }^{30}$ y se figura con la presencia de testigos en una ilustración del manuscrito alemán de 1638 de fray Juan Ludovico de la Asunción, conservado en la biblioteca de los Carmelitas de Regensburg (Fig. 7), en el que santa Teresa hace las veces de psicopompo, conduciendo a una de sus seguidoras al cielo.

Santa Teresa es maestra de oración ${ }^{31}$ y en este sentido son numerosas las obras que la presentan orando en el momento en que es observada por sus compañeras del monasterio, siendo uno de los hitos cruciales de la iconografía teresiana el que figura su verdadera conversión, que se produce en el oratorio conventual ante una imagen de Cristo llagado ${ }^{32}$ (Fig. 8). La visión de la imagen del Ecce Homo, que aparece en numerosas series, se produjo en 1553 cuando atravesaba el oratorio: "Era de Cristo muy llagado, y tan devota, que mirándola, toda me turbó de verla tal, porque representaba bien lo que pasó por nosotros. Fue tanto lo que sentí de lo mal que había agradecido aquellas llagas, que el corazón me parece se me partía, y arrojome cabe Él con grandísimo derramamiento de lágrimas, suplicándole me fortaleciese ya de una vez para no ofenderle" 33 . Gutiérrez Rueda ${ }^{34}$ recoge la tradición carmelitana de que no se trataba de una pintura sino de una talla policromada, "una imagen que habían traído allí a guardar, que se había buscado para cierta fiesta que se hacía en casa" ${ }^{35}$; pero la estampa de la Vita presenta a la santa arrodillada delan-

\footnotetext{
28 “Ab obitu, permultis illustri fulgens gloriâ apparet; praecipue verò in Segobiensi discalceatarum Ordinis sui monasterio, tribus pariter monialibus in Chori recessu, se conspiciendam familiariter exhibit" (Desde su muerte se les aparece a muchos reluciendo en brillante gloria; especialmente, en el convento de Segovia de su Orden de descalzas, se muestra familiarmente a tres monjas a la vez para que la vean en el trascoro).

29 Santa Teresa de Jesús, Fundaciones: 31, 47.

${ }^{30}$ Moreno Cuadro, 2010: 53.

31 Sobre la oración teresiana, véanse LuIS JAVIER DE LA InMACUladA, 1964:169-301; HerRÁIz GARCía, 1982.

32 "Ante Christi plagis tumentis imaginem, pro vital in melius mutatione feruenter orans, tota protinus immutata, postulatam gratiam consequitur; paucis inde post diebus, hanc vocem a Deo perciptens; Posthac cum angelis conuersaberis" (Orando fervorosamente ante una imagen de Cristo cubierto de llagas, en pro de una mudanza a mejor de su vida, se transforma por completo y consigue la gracia solicitada, escuchando a los pocos días estas palabras procedentes de Dios: En adelante conversarás con los ángeles).

33 SANTA Teresa de Jesús, Vida: 9, 1.

34 GutiÉRRez Rueda, 1964: 25.

35 SANTA Teresa de Jesús, Vida: 9, 1.
}

Arch. esp. arte, LXXXVII, 345, ENERO-MARZO 2014, 29-44 ISSN: 0004-0428, eISSN: 1988-8511, doi: 10.3989/aearte.2014.03 

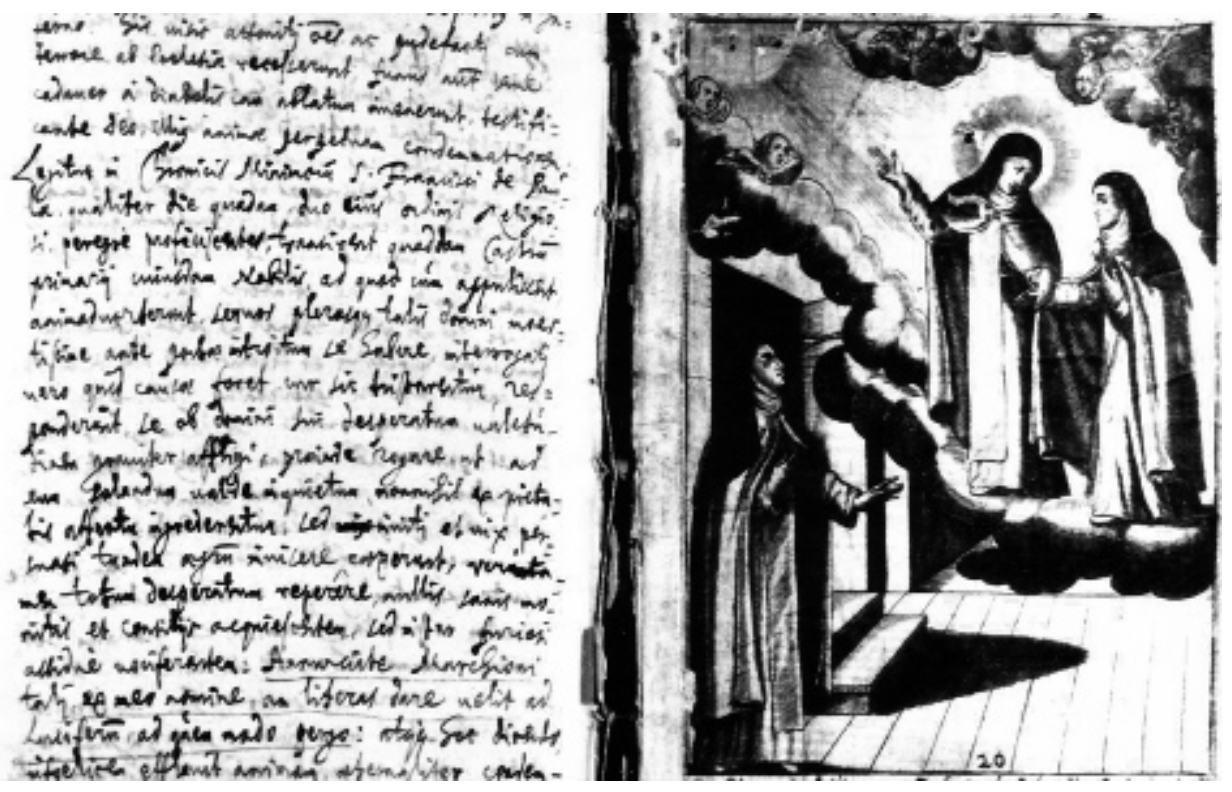

Fig. 7. Santa Teresa conduciendo a una descalza a la divinidad, en Terror moniturus..., manuscrito, Biblioteca de los Carmelitas de Regensburg, Alemania.

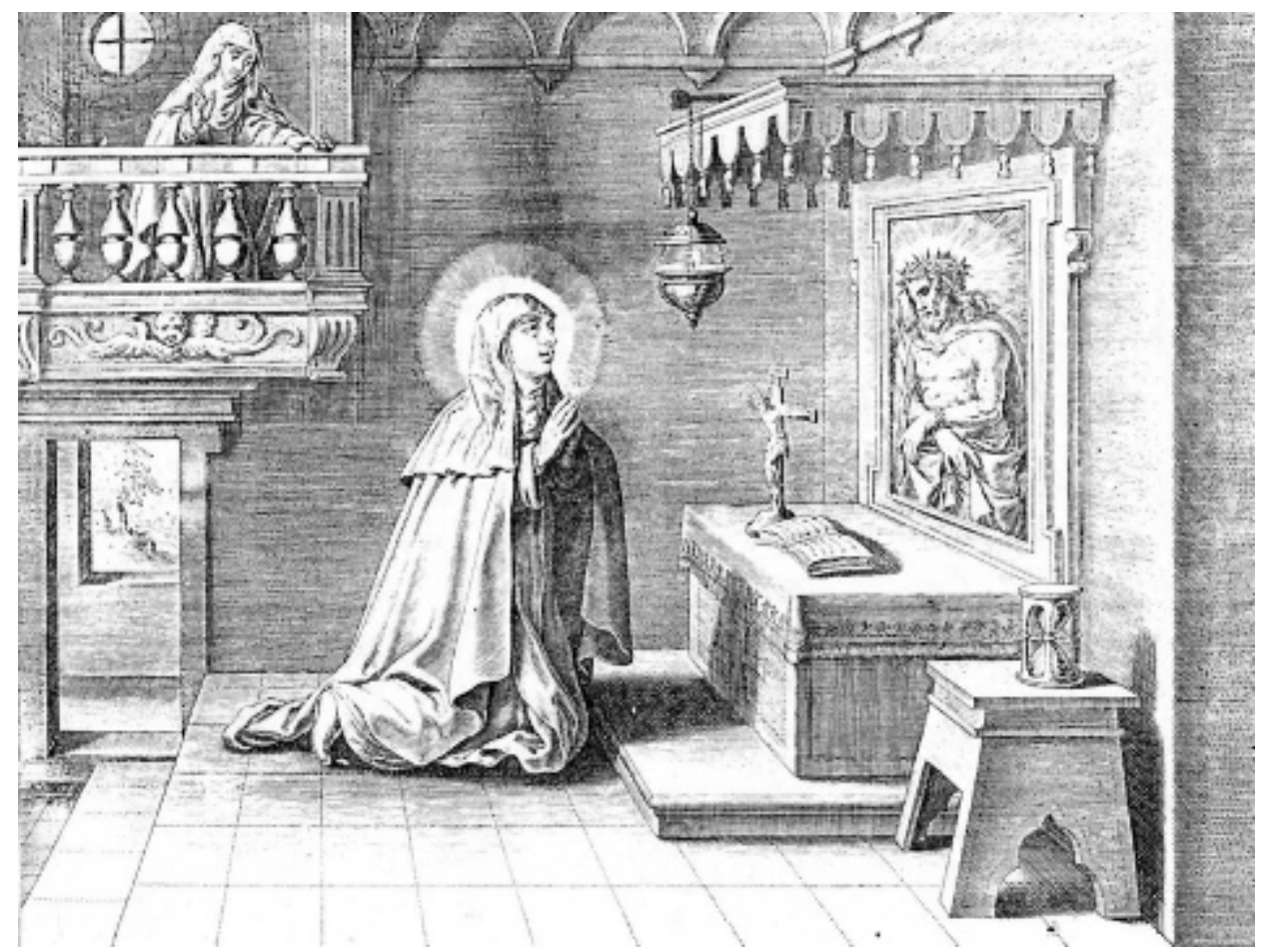

Fig. 8. Conversión de Santa Teresa, en Vita B. Virginis Teresiae..., Amberes, 1613. Teresianum de Roma.

Arch. esp. arte, LXXXVII, 345, ENERO-MARZO 2014, 29-44

ISSN: 0004-0428, eISSN: 1988-8511, doi: 10.3989/aearte.2014.03 
te de un cuadro en el frente de un pequeño altar con un libro y un crucifijo, como es frecuente en las representaciones de Teresa orando en su celda, lugar donde ubica Ribera la escena ${ }^{36}$, aunque lo más probable es que se produjera en el oratorio del convento, como parece subrayar también la estampa comentada en la que se ha representado una tribuna con una carmelita contemplando el suceso. Junto a la mesa de altar hay una banqueta -"in cornu altaris"- con un reloj de arena y como protagonista principal el cuadro del Ecce Homo bajo dosel, que cambia en otras estampas de la serie, en la que se ha representado el mismo lienzo, en las que Cristo no porta la tradicional caña como cetro sino una vara, como en La coronación de espinas de Antón van Dyck del Museo del Prado ${ }^{37}$.

Independientemente de que fuera una pintura o una escultura, la experiencia teresiana se produce delante de una imagen, subrayando la importancia de las mismas y el papel fundamental que adquieren en su iconografía, especialmente la de Cristo, que contempla en diferentes obras artísticas, además de en las visiones, como la comentada del monasterio de la Encarnación de Ávila y el dibujo de Duruelo ${ }^{38}$, y la de María en el retablo de Mancera ${ }^{39}$, afianzando el valor de la imagen con una función esencialmente religiosa que permite al fiel adentrarse en la realidad de lo representado, como reflejan las palabras de la propia santa cuando narra el episodio: "Fue tanto lo que sentí de lo mal que había agradecido aquellas llagas, que el corazón me parece se me partía"40; aunque una Relación de 1572 recoge la tentación que tuvo de despreciarlas por considerarlas contrarias a la pobreza: "Yo había leído en un libro que era una imperfección el tener imágenes artísticas, por lo tanto no quería conservar en mi celda la que allí se encontraba. Antes incluso de haber leído esto, me había parecido coherente con la pobreza el poseer sólo imágenes de papel, y cuando leí lo que acabo de mencionar, decidí que no podía conservar otras. Cuando menos lo pensaba, oí 'No es una buena mortificación, ¿Qué se debe preferir? ¿La pobreza o la caridad?'. Puesto que el amor es preferible, no tenía que renunciar a nada que lo pudiera avivar, ni hacer renunciar a mis religiosas, porque el libro hablaba de la abundancia de molduras y de cosas artísticas en torno a las imágenes, y no de la imagen en sí" ${ }^{\prime \prime 1}$.

En este ambiente hay que situar el lienzo de la primera mitad del siglo XVII de la Colección Carmelitana de Francia ${ }^{42}$, que representa La coronación de santa Teresa (Fig. 9), en el que Cristo sustituye la imagen del altar ante el que se ubica la reformadora descalza, que se encuentra en la iglesia conventual al recibir la corona, momento que es presenciado por la comunidad desde el coro. Separación de planos entre personajes y testigos que contemplan la escena en una ajustada interpretación del suceso ${ }^{43}$ que permite al anónimo pintor crear una imagen más aérea de Cristo que la de la Vita al presentarlo de medio cuerpo entre nubes sobre el altar-como algunas

6 RiBERA, 1590: 1. I. c. IX.

37 DíAZ PADRÓN, 1975: 98-100, lám. 70.

38 SANTA TERESA DE Jesús, Fundaciones: $14,6$.

39 SANTA Teresa de Jesús, Fundaciones: $14,9$.

40 Santa Teresa de Jesús, Vida: 9,1-3.

41 'J'avais lu dans un livre que c'est une imperfection d'avoir des images artistiques, je ne voulais donc pas garder dans ma cellulle celle qui y était. Avant même d'avoir lu cela, il m'avait semblé conforme à la pauvreté de n'avoir que des images de papier, et lorsque j'eus lu ce que je viens de citer, je décidai de ne pas en conserver d'autres. Lorsque j'y pensais le moins, j'entandis: 'Ce n'est pas una bonne mortification; que doit-on préférer, la pauvreté ou la charité? Puisque l'amour est préferable, je devais ne renoncer à rien de ce qui l'éveille, ni faire renoncer mes religieuses, car le livre parlait de l'abondance de moulures et de choses artistiques autour des images, non de l'image elle-même"', Cfr. L'Art du XVIIe siècle dans les Carmels de France, 1982: 39.

${ }^{42}$ L'Art du XVIIe siècle dans les Carmels de France, 1982: 55.

43 SAnta Teresa de Jesús, Vida: 36, 24: "estando haciendo oración en la iglesia antes que entrase en el monasterio, y estando casi en arrobamiento, vi a Cristo, que con grande amor me pareció me recibía y ponía una corona, y agradeciéndome lo que había hecho por su Madre".

Arch. esp. arte, LXXXVII, 345, ENERO-MARZO 2014, 29-44 ISSN: 0004-0428, eISSN: 1988-8511, doi: 10.3989/aearte.2014.03 


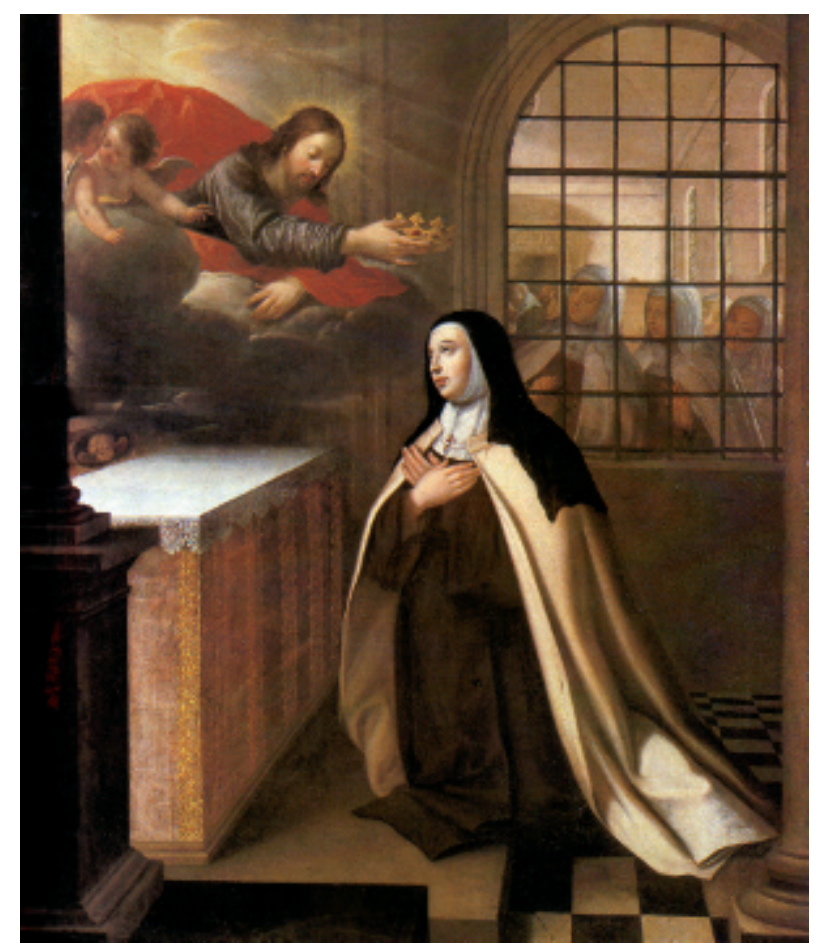

Fig. 9. Santa Teresa coronada por Cristo. Colección Carmelitana de Francia.

apariciones del Nazareno a san Juan de la Cruz-, respondiendo a la espiritualidad carmelitana y a los esquemas compositivos que tuvieron un gran arraigo en Francia, pues con ligeras variantes -eliminación de la reja del coro y personajes presentes en la iglesia- es el que se sigue en las estampas de la Vie y la Vita, publicadas en Lyon y Roma respectivamente en 1670, que representan la aparición de Cristo a santa Teresa para que se apiadara de los que infringían a la Iglesia ${ }^{44}$.

Los testimonios de los testigos se amplían a las propias visiones de la santa, incidiendo en la relación que tenía con la divinidad, que no solo se preocupa de su alma sino de su cuerpo, lo que se recoge -presenciado por testigos- en las estampas de las series de 1670 que figuran a Cristo confortando a santa Teresa ${ }^{45}$. De la singular escena conocemos una versión simplificada de Cornelis van Merlen (1666-1733) que figura a santa Teresa sentada junto a una mesa y a Cristo ofreciéndole un trozo de pan, de forma más natural que en las series de 1670, en las que parece estar comulgando de manos de Cristo -alegoría eucarística de Cristo Sacerdote que recalca en la postura contrarreformista de la comunión frecuente en la que insistiremos más adelante. La comida mística fue recogida por el padre Diego de Yepes -"Y otra vez (como ella dexó escrito en un papel) le hizo el Señor otro regalado favor, estando una vez (dice) con la pena que traigo de que estoy ausente de Dios, y estos días había sido bien grande, que parecía no la podía sufrir, y habiendo estado ansí harto fatigada, ví que era tarde para hacer colación y no podía, y a causa de los vómitos háceme mucha flaqueza, no la hacer un rato antes, y así con harta fuerza, puse el pan delante para hacer a comerlo, y luego se me representó allí Cristo, y parecía que me partía el pan, y me lo ponía en la boca, y díxome: 'come hija, y pasa como pudieres, bien veo lo que padeces, más esto te conviene ahora"" 46 - y sus representaciones son abundantes ${ }^{47}$ y muy variadas, completándose en ocasiones con numerosas figuras, como en el lienzo setecentista del Mu-

${ }^{44}$ La Vie de la seraphiqve Mere Sainte Teresa de Iesvs..., 1670: imagen 38; Vita Effigiata et Essercizi Affettivi di s. Teresa di Giesv..., 1670: 252; Vita Effigiata Della Serafica Vergine S. Teresa di Gesù..., 1715: lám. XI.

${ }^{45}$ Los pies de ambas estampas son idénticos, si bien la estampa de Lyon elimina la expresión "fidissima sponsam": "Rex gloria Teresiam v. fidissimam Sponsam / Aegrotantem inuisit, pane, correcto reficit / et ad morbi tolerantiam hortatur" (El Rey de la Gloria visita a su fidelísima esposa la virgen Teresa, que está enferma, la reconforta con el pan que le ofrece y la anima a que soporte la enfermedad).

46 YePES, 1606: 1. I, c. XIX.

47 Gutiérrez RuedA, 1964: 91, recoge un cuadro de la colección del marqués de Piedras Albas de Madrid, parecido al conservado en el monasterio de MM.CC.DD. de Toledo, de más calidad ambos que el lienzo de la capilla de la Biblioteca Teresiana de Ávila que figura la visión milagrosa.

Arch. esp. arte, LXXXVII, 345, ENERO-MARZO 2014, 29-44

ISSN: 0004-0428, eISSN: 1988-8511, doi: 10.3989/aearte.2014.03 


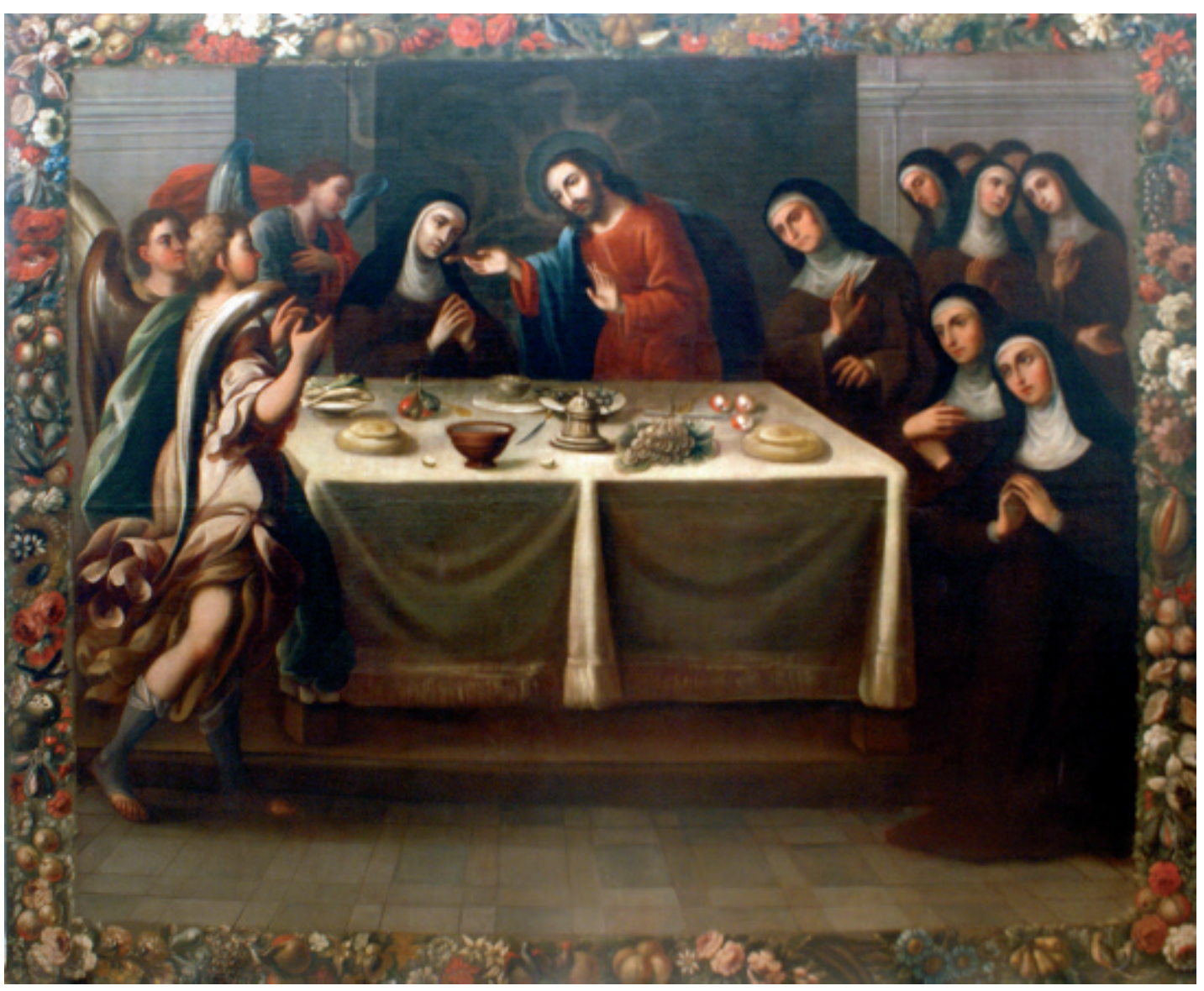

Fig. 10. Cristo confortando a santa Teresa. Museo Regional de Guadalajara, México.

seo Regional de Guadalajara (México), en el que aparecen en torno a la mesa del refectorio ${ }^{48}$ la comunidad de descalzas y un nutrido grupo de ángeles (Fig. 10).

La trascendencia de los testimonios de los testigos va más allá de apoyar la solicitud ante la Congregación para las Causas de los Santos, convirtiéndose en una catequesis de la doctrina teresiana, que se ofrece como ejemplo, incidiendo en la última idea de la dedicatoria de la Vita de Amberes -suscitet aemulationem (suscite la imitación)-, reeditada en 1630, diecisiete años antes de que Gianlorenzo Bernini iniciara el encargo del cardenal Federico Cornaro en la iglesia carmelitana de Santa Maria della Vittoria de Roma (1647-1652) para el que, sin duda, utilizó como fuente de inspiración la serie de Collaert-Galle, la más importante fuente para la iconografía teresiana durante los dos primeros tercios del siglo XVII, hasta las grandes series de 1670, que se renovó ligeramente con motivo de la canonización, insistiendo fundamentalmente en la transverberación, el gran tema que fue motivo central teresiano de la estampa oficial grabada por Matteo Greuter para las ceremonias oficiales de 1622, representación que estuvo rodeada por ocho milagros que se recogieron en la bula papal: Multiplicación de la harina en el monasterio de Villanueva de la Jara, curación de Ana de la Trinidad en Medina del Campo, curación de la

48 Santa Teresa de Jesús, Cuentas de Conciencia: $12,3$.

Arch. esp. arte, LXXXVII, 345, ENERO-MARZO 2014, 29-44 ISSN: 0004-0428, eISSN: 1988-8511, doi: 10.3989/aearte.2014.03 

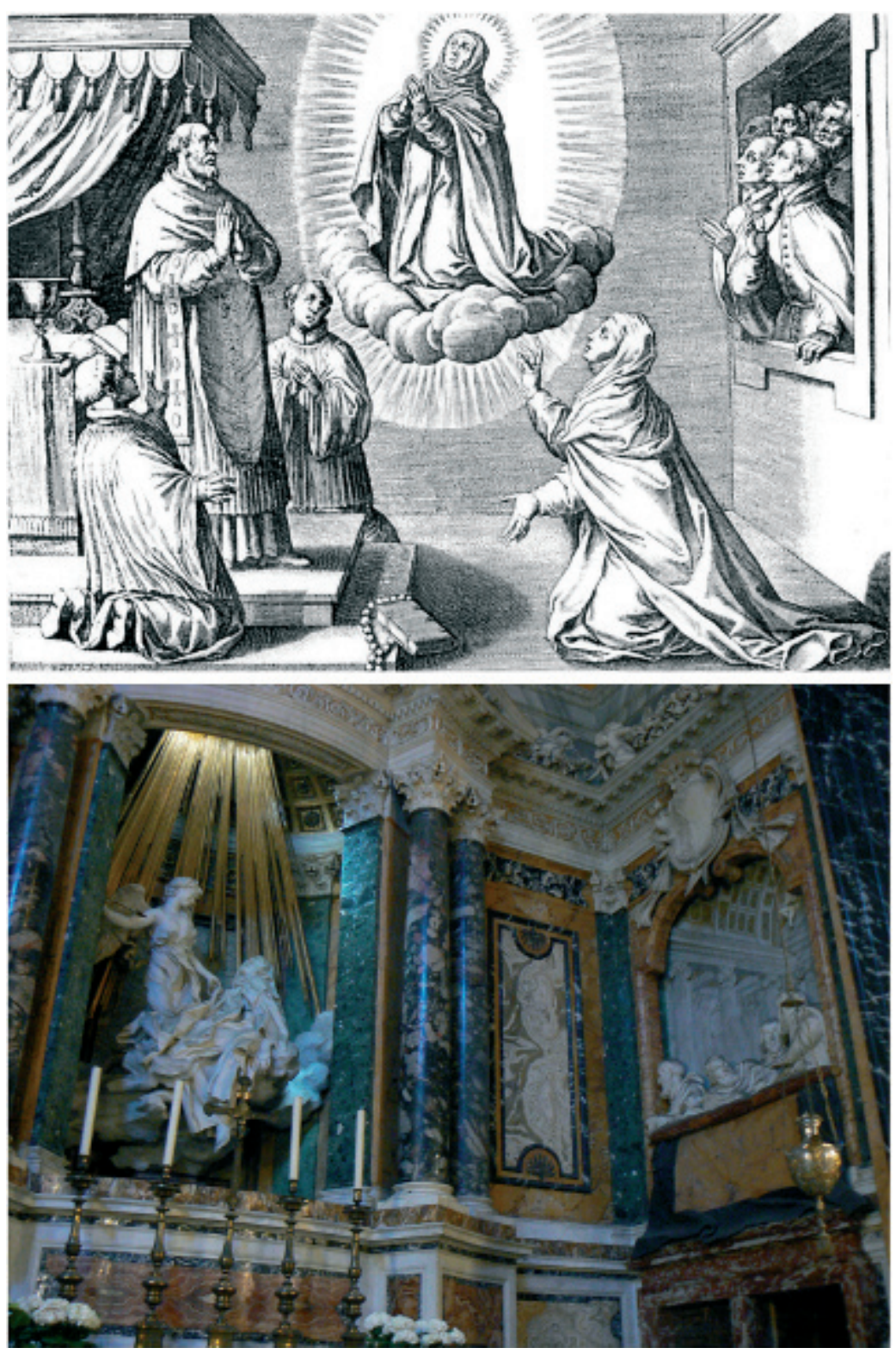

Fig. 11. Adrian Collaert, Levitación de Santa Teresa al recibir la comunión de manos del obispo de Ávila, en Vita B. Virginis Teresiae...., Amberes, 1613. Teresianum de Roma (arriba) y Gianlorenzo Bernini, Extasis de Santa Teresa, capilla Cornaro, Santa Maria della Vittoria, Roma (abajo).

priora de Medina del Campo, el árbol revivificado en el momento de la muerte de santa Teresa, la curación de un niño, la curación de una carmelita que había perdido el olfato, la curación de Ana de San Miguel y la curación de Francisco Pérez ${ }^{49}$, temas secundarios de la citada estampa que no se mantuvieron en la iconografía teresiana.

La estampa de Collaert utilizada por Bernini para el planteamiento general de su magistral obra en la iglesia carmelitana presenta una visión directa de la Levitación de santa Teresa al

49 MÂLE, 1932: 99.

Arch. esp. arte, LXXXVII, 345, ENERO-MARZO 2014, 29-44

ISSN: 0004-0428, eISSN: 1988-8511, doi: 10.3989/aearte.2014.03 
recibir la comunión de manos del obispo de Ávila (Fig. 11), que se encuadra en la línea promulgada por Trento de que los fieles asistentes a las misas recibieran la comunión, muy defendida por san Ignacio de Loyola ${ }^{50}$ y el Maestro Juan de Ávila ${ }^{51}$ frente a quienes recomendaban abstenerse de recibir la Eucaristía en una postura que llevó a muchos fieles a no comulgar por no considerarse preparados para ello, a lo que contribuyó el rigorismo del jansenismo antijesuítico del siglo XVII ${ }^{52}$. Son muchas las obras que figuran la comunión de santa Teresa, entre las que destaca la representación del hecho prodigioso de la Sagrada Forma dirigiéndose a la reformadora desde la mano del sacerdote cuando se acercó a comulgar ${ }^{53}$. Esta singular visión que presentan las grandes series teresianas no tuvo un amplio desarrollo en las artes plásticas, en las que si fue relativamente frecuente la representación de la santa comulgando de manos de san Pedro de Alcántara, canonizado en 1669 junto a santa María Magdalena de Pazzi, a la que se dedicó la Vita iconibus expresa, que creemos fue el detonante para impulsar la iconografía teresiana con las grandes series de 1670 y asimismo el momento de la revitalización de la iconografía alcantarina, realizándose varias pinturas de esta temática ${ }^{54}$.

Pero la estampa de Collaert, además de subrayar la práctica de la comunión, quiere representar el estado frecuente ${ }^{55}$ de Teresa en unión con Cristo, presente en la Eucaristía que perpetúa el sacrificio redentor de la cruz. Asistiendo a misa o después de comulgar la santa tuvo visiones imaginarias de Cristo $^{56}$ que posibilitaron la unión mística, presentándose en la Idea Vitae Teresianae el deseo de sentir la elevación -Vis sentire sublevamen ${ }^{57}$ - y en Las Moradas el matrimonio espiritual, escribiendo que la "primera vez que Dios hace esta merced quiere su Majestad mostrarle al alma por visión imaginaria de su sacratísima Humanidad, para que lo entienda bien y no esté ignorante de que recibe tan soberano don. A otras personas será por otra forma, a ésta de quien hablamos, se la presentó el Señor, acabando de comulgar, con forma de gran resplandor y hermosura y majestad, como después de resucitado, y le dijo que ya era tiempo de que sus cosas tomase ella por suyas, y Él tendría cuidado de las suyas, y otras palabras que son más para sentir que para decir" 58 , sentimiento de unión con Dios que le hace estar totalmente fuera de las cosas de este mundo, "Pues cuando está en el arrobamiento, el cuerpo queda como muerto, sin poder nada de sí muchas veces, y como le toma se queda: si en pie, si sentado, si las manos abiertas, si cerradas" 59 .

La experiencia teresiana de $\operatorname{Dios}^{60}$ que ha sido más difundida por la Historia del Arte es la del ángel traspasándole el corazón con el dardo de Amor divino, máximo exponente de la unión con Dios que narra santa Teresa en su Vida ${ }^{61}$. Entre los ejemplares más emblemáticos hay que

0 Berguiriztáin, 1909: 48.

51 ESQUERDA BIFET, 1999: 192-194.

52 Sobre el Jansenismo, véase BihLMEYeR-TueChle, 1988: v. 4.

53 "S. V. Teresia mortalem uitam pertaesa / coelesto cibo, diuina uirtute ad ipsam / è Ministri manu delato reficitur" (La santa virgen Teresa, hastiada de la vida mortal, se repone con el alimento celestial, que por virtud divina se dirige a ella desde la mano del ministro). El pie de la estampa de Lyon elimina la expresión "hastiada de la vida mortal".

54 ANDRÉS ORDAX, 2002: 186-189.

55 "Augustissimum Eucharistiae Sacramentum e manibus abulensis Antistitis, praesentibus monialibus, in nouo monasterio receptura, corpore in aerem, quod frequens eidem erat, mirabiliter extollitur" (Al ir a recibir el santísimo sacramento de la Eucaristía de manos del obispo de Ávila en un nuevo convento, ante la presencia de las monjas, se eleva milagrosamente con el cuerpo por los aires, cosa que le sucedía con frecuencia).

${ }^{56}$ Recogido por Ribera, 1590: 1. II, c. XI, además de por SANTA Teresa DE Jesús, entre otras citas, en Vida: 28, 3 y Relaciones: III, 15,6.

${ }^{57}$ Idea Vitae Teresianae iconibus symbolicis expressa: 67.

58 Santa Teresa de Jesús, Las Moradas: VII, c. $2,1$.

59 SANTA Teresa de Jesús, Vida: 20, 18.

60 Chevalier, 1956: 669-687.

61 SANTA Teresa de Jesús, Vida: 29, 13.

Arch. esp. arte, LXXXVII, 345, ENERO-MARZO 2014, 29-44 ISSN: 0004-0428, eISSN: 1988-8511, doi: 10.3989/aearte.2014.03 
destacar el Éxtasis de Santa Teresa de Gianlorenzo Bernini' ${ }^{62}$, sin duda uno de los logros más perfectos del genial artista, en el que trasciende los modos tradicionales, con excepcionales relaciones de color, en las que destaca la blancura del grupo que acentúa el dramatismo de la escena y la teatralidad del conjunto, presentando la transverberación de santa Teresa sobre una nube suspendida, iluminada por un foco de luz amarillenta -especialmente efectista al atardecer, subrayando lo efímero del momento representado- con sus connotaciones simbólicas, fundamentalmente dirigida a la persona que recibe la gracia divina, que introduce a los fieles en la experiencia sobrenatural que contemplan, trasladando a la importante capilla, concebida como un enorme lienzo, la ilusión interpretada por los pintores ${ }^{63}$.

Entre los fieles y los testigos de la Vita de 1613 se han destacado, en los palcos laterales, siete cardenales y un duque de la familia Cornaro -obra de los mejores discípulos de Bernini ${ }^{64}-$, singulares "testigos de referencia" de la experiencia mística teresiana que implican al espectador, el cual se adentra en la escena como un testigo más que participa de la espiritualidad teresiana.

\section{BIBLIOGRAFÍA}

Andrés Ordax, S., Arte e iconografía de San Pedro de Alcántara. Ávila, 2002.

Berguiriztáin, J., San Ignacio de Loyola. Apóstol de la comunión frecuente. Barcelona, 1909.

Bihlmeyer, K. - Tuechle, H., Storia della Chiesa, Brescia: Ed. Marcelliana, 1988. v. 4.

Calvo Castellón, A., "Chavarito, un pintor granadino, 1662-1751", en Cuadernos de Arte, t. XX, n. 25 (1975), pp. 256 ss.

Chevalier, J., "Sainte Thérèse d'Ávila et l'expérience de Dieu", en Histoire de la Pensé, París, 1956.

De la Inmaculada, Luis Javier, "Una nueva estructura del método carmelitano de oración”, en Monte Carmelo, 72 (1964), pp. 169-301.

Di Bernardo, Pier Paolo Un carmelitano per la nuova Europa, Edizioni Grafiche, Roma 1994.

Díaz Padrón, M., Museo del Prado. Catálogo de Pinturas I. Escuela Flamenca. Siglo XVII. Madrid, 1975.

Emond, C., L'Iconographie Carmélitaine dans les anciens Pays-Bas méridionaux. Bruselas, 1961.

Esquerda Bifet, J., "Comunión eucarística", en Diccionario de San Juan de Ávila. Burgos: Monte Carmelo, 1999, pp. 192-194.

Gil de Muro, Eduardo T., Como una suave melodía. Burgos, Monte Carmelo, 1996.

Gutiérrez Haces, J. et al.: Cristóbal de Villalpando. ca. 1649-1714. Catálogo razonado. México, Instituto de Investigaciones Estéticas, 1997.

Gutiérrez Rueda, L., "Ensayo de iconografía teresiana", en Revista de Espiritualidad, 90, 1964.

Herráiz García, A, M., La oración, historia de amistad. Madrid, Ed. Espiritualidad, 1982.

Idea / Vitae Teresianae / iconobus symbolicis / expressa, / in quinqué partes divisa. / Prima figurat sui cognitionem, / secunda sui mortificationem, / tertia virtutum acquisitionem, / quarta mentales orationem, / quinta divinam contemplationem. Dedicata Reverendo Adm. In ChristôPatri Observantissimo. / Rdo. Patri Huberto a S. Ioanne Baptista, / Carmelitliarum Deiscalceatorum per Flandô-Belgium Provinciali. Antverpiae, Extant Venales, apud Jacobum Mesens.

Kuhn, R., "Die Unio Mystica der Hl. Therese von Avila von Lorenzo Bernini in der Kornaro Kapelle in Rom", en Alte un Moderne Kunst, XII (1967), pp. 2-8.

L'Art du XVIIe siècle dans les Carmels de France. Catálogo de la exposición celebrada en el Musée du Petit Palais (17 de nov. 1982 - 15 febr. 1983). París, ediciones Yves Rocher, 1982.

\footnotetext{
62 KUHN, 1967: 2-8.

63 WittKower, 1979: 157-160. Sobre la integración de las artes en Bernini, véase IRVING LaVIN, 1980.

64 Santa María de la Victoria, 1999: 15.
}

Arch. esp. arte, LXXXVII, 345, ENERO-MARZO 2014, 29-44

ISSN: 0004-0428, eISSN: 1988-8511, doi: 10.3989/aearte.2014.03 
La Vie de la seraphiqve Mere Sainte Teresa de Iesvs, fondatrice des Carmes Déchaussez \& Carmelites Déchaussées, en Figuras, \& en Vers François \& Latins. Avec un Abbregé de l'Histoire, une Reflexion Morale, \& une Resolution Chrétienne sur châque Figura, Lyon 1670.

Lavin, I., Bernini and the Unity of the Visual Arts, Oxford University Press, The Pierpont Morgan Library, 2 vols. New York and London, 1980. Traducción italiana Bernini e l'unità delle arti visive, Roma, Edizioni dell'Elefante, 1980.

Llompart, G., "Spiritualis monachus: aportación a la iconografía del perfecto religioso", en Analecta Sacra Tarraconensia 38 (1965), pp. 159-172.

Llompart, G., "El fresco de la religiosa crucificada de las Descalas Reales de Madrid", en Traza y Baza, 3 (1973), pp. 54-55.

Mâle, E., L'art religieux de la fin du XVIe siècle, du XVIIe siècle et du XVIIIe siècle. Paris, 1932.

Meboldk, L., Catálogo de pintura colonial en Chile. Universidad Católica de Chile. Santiago de Chile, 1985.

Mesa, J. - Gisbert, T., Historia de la pintura cuzqueña. Buenos Aires, 1962.

Moreno Cuadro, F., "Juan Bernabé Palomino y Johann Hiebel. Tradición y renovación en las series teresianas del setecientos", en Academia, Boletín de la Real Academia de Bellas Artes de San Fernando, 110111 (2010), pp. 37-64.

Portman, K., "Een emblematische Voorstelling van het mystieke leven: de Idea vitae teresianae..., c. 1686", en Ons Geestelijk Erf, 48 (1974), pp. 46-66.

Procesos de beatificación y canonización de Santa Teresa de Jesús, edición de Silverio de Santa Teresa, Burgos, Biblioteca Mística Carmelitana, 1934-1935.

Ribera, F., La vida de la Madre Teresa de Jesús. 1590.

Ripa, C., Iconología. Ed. Akal/Arte Estética, Madrid, 1987.

Santa María de la Victoria, Roma, ATS Italia Editrice, 1999.

Santa Teresa de Jesús, Obras Completas, B.A.C., 2012.

Urrea, J., "El pintor García Hidalgo", en Archivo Español de Arte, XLVIII (1975), pp. 78 ss.

Vita Effigiata della Seráfica Vergine S. Teresa di Gesù fondatrice dell'Ordine Carmelita Scalzo, Roma, 1715.

Vita Effigiata et Essercizi Affettivi di s. Teresa di Giesv Maestra di Celeste Doctrina, Roma, 1670.

Wittkower, R., Arte y arquitectura en Italia, 1660-1750. Manuales Arte Cátedra. Madrid, 1979.

Yepes, D. de, Vida, virtudes, milagros de la Bienaventurada Virgen Teresa de Jesús, Madre y Fundadora de la nueva Reformación de la Orden de los Descalços y Descalças de Nuestra Señora del Carmen. Zaragoza, 1606.

Fecha de recepción: 16-I-2012

Fecha de aceptación: 3-VII-2013

Arch. esp. arte, LXXXVII, 345, ENERO-MARZO 2014, 29-44 ISSN: 0004-0428, eISSN: 1988-8511, doi: 10.3989/aearte.2014.03 